\title{
EI Financiamiento de la Educación Superior en Inglaterra
}

\author{
Bahram Bekhradnia, \\ Director of Policy \\ Higher Education Funding Council for England ${ }^{1}$
}

Las universidades del Reino Unido son entidades autónomas, independientes, que no pertenecen al Estado, aunque sus ingresos dependen en mayor o menor grado de la recaudación tributaria. El Estado decide la proporción de impuestos que debe destinarse a la educación superior y define ciertas metas de política de alto nivel. Más allá de eso, su papel es sumamente limitado. Por ejemplo, en particular, no participa en la decisión de cuánto dinero debe suministrarse a cada establecimiento. La ley le prohíbe intervenir en tales decisiones, que quedan reservadas para los Consejos de Financiamiento de la Educación Superior que operan en Inglaterra, Escocia y Gales. El Consejo de Financiamiento de la Educación Superior de Inglaterra (CFESI) es un organismo de derecho público, cuya función primordial es distribuir los fondos (aproximadamente 5 000 millones de libras esterlinas, esto es, 7500 millones de dólares) que el gobierno asigna en forma anual a la educación superior. Pero, en realidad, el presupuesto del gobierno es considerablemente más alto para este fin, pues en dicho monto no figura la subvención que otorga por concepto de aranceles estudiantiles, ni tampoco una fracción importante de los recursos destinados a investigación.

EI CFESI es la creación más reciente en de la línea de los llamados organismos amortiguadores, el primero de los cuales fue la Comisión de Subvenciones para las Universidades (CSU), fundada en 1919. Es interesante examinar porqué se creó la CSU. Con anterioridad, el Estado no había tenido mayor participación en el financiamiento de las universidades, pero a medida que comenzó a intervenir cada vez más, se hizo sentir en forma también creciente la inquietud de que aprovechara su poder financiero para influir en materias académicas $y$, de ese modo, pusiera en peligro la libertad que debe imperar en este ámbito. Así nació este organismo amortiguador. Al parecer, a comienzos del siglo $\mathrm{XX}$, los políticos inspiraban tan poca confianza como a comienzos del siglo XXI.

Universidades autónomas e independientes

La autonomía e independencia de las universidades del Reino Unido es una realidad, y ejerce poderosa influencia en el modo en que son financiadas. La autonomía abarca todos los aspectos de su funcionamiento. En materias administrativas, por ejemplo, la autoridad máxima recae en el Consejo de la universidad, cuyos miembros son elegidos de entre sus integrantes, y ni el gobierno, ni

1 (Consejo de Financiamiento de la Educación Superior de Inglaterra (CFESI) 
los Consejos de Financiamiento tienen participación alguna en su designación.

En lo académico, las universidades definen su propio currículo, sus propios estándares, conceden sus propios títulos y deciden autónomamente qué programas ofrecerán. Si una universidad desea cerrar el departamento de física - como lo han hecho algunas hace poco tiempo en Inglaterra- y reemplazarlo por uno de psicología, es enteramente libre de hacerlo, sin necesidad de consultar a ningún otro organismo.

Con todo, lo más notable es la autonomía financiera de nuestras universidades. El CFESI calcula con bastante detalle el monto de los fondos que ha de recibir cada universidad, mediante un procedimiento establecido. Pero, una vez adoptada la decisión sobre el monto total que ha de percibir la universidad, la subvención correspondiente se le entrega de una vez, en un solo bloque. Solo una fracción muy pequeña del monto total aportado a las universidades se asigna para fines especiales, pues más del $90 \%$ de ese total es absorbido por la subvención en bloque, y corresponderá a cada universidad gastarla, según estime conveniente. Si la universidad desea cerrar un departamento y abrir otro, puede hacerlo, dentro de los límites de los fondos recibidos. También puede contratar menos personal y aprovechar el dinero así liberado para comprar computadoras. Y lo mismo ocurre si desea gastar menos en bibliotecas 0 en remuneraciones y más en laboratorios. La subvención en un solo bloque es una realidad, y constituye un poderoso instrumento dentro del arsenal de la autonomía. Todo, desde el presupuesto para remuneraciones hasta el dinero destinado a obras de infraestructura, entra en esa subvención única, y la universidad está facultada para gastarla como mejor le parezca.

También es importante para la autonomía universitaria el hecho de que si bien la subvención se entrega cada año, las universidades no están obligadas a gastarla en su totalidad en el curso de ese mismo año. En efecto, pueden acumular reservas $y$, en realidad, se espera que lo hagan. Tienen capacidad para contraer deudas ( $\mathrm{si}$ el banco se lo permite.) Asimismo, pueden solicitar crédito para construir obras de infraestructura. Algunas universidades del Reino Unido, incluso, han emitido bonos en el mercado financiero.

Como consecuencia del grado considerable de autonomía logrado, la gestión de las universidades se ha vuelto un asunto complejo, desde el punto de vista administrativo. Es teóricamente posible -aunque espero que jamás ocurra- que una universidad caiga finalmente en bancarrota. Su destino financiero está en sus propias manos. Fijamos condiciones para la subvención, a fin de minimizar las posibilidades de que algo salga mal. Por ejemplo, las universidades deben contar con nuestra aprobación antes de solicitar un préstamo que exceda cierto porcentaje de sus ingresos. Y haremos cuanto esté a nuestro alcance, salvo entregar sumas adicionales de dinero, para ayudar a aquellas que se vean en problemas económicos. Vigilamos estrechamente la salud financiera de todas las universidades. Exigimos informes 
semestrales al respecto, y no vacilamos en actuar apenas asoman las primeras dificultades. Pero, en definitiva, recae en ellas la responsabilidad de solucionar sus propios problemas.

\section{Rendición de cuentas}

La otra cara de la medalla de la autonomía es la rendición de cuentas. $Y$, en este sentido, pesan grandes exigencias sobre las universidades. En primer lugar, están sujetas a riguroso escrutinio contable, que las obliga a presentar cuentas públicas de su estado financiero, las cuales son examinadas todos los años por contadores externos; deben llevar una verificación interna de cuentas y disponer de una comisión independiente para ello; nuestros auditores examinan cada tres años a las distintas universidades, y la Oficina de Revisión de Cuentas del país - esto es, los auditores del Parlamento- también puede fiscalizarlas. Ello deja a las universidades poco espacio para cualquier tipo de irregularidad financiera. Asimismo, están obligadas a rendir cuentas sobre la calidad de sus resultados. En Inglaterra operan mecanismos sólidamente arraigados para evaluar la calidad de la investigación y de la enseñanza. Respecto a la investigación, el procedimiento es en extremo riguroso, porque su dictamen influye directamente en el monto del financiamiento otorgado a cada universidad. En contraste, no hay vínculo entre el financiamiento y la calidad de la enseñanza (a menos que fuera en extremo mediocre cosa poco frecuente-, y en ese caso, dejaríamos de entregar fondos), pero son evaluadas todas las materias impartidas en las universidades y se hacen públicos los informes correspondientes. Incluso, si no hay vínculo con el financiamiento, las universidades toman muy en serio las evaluaciones relativas a la calidad de la enseñanza.

Fuentes de subvención

Otro aspecto que debe considerarse respecto a las universidades inglesas es que disponen de múltiples fuentes de financiación. En lo que se refiere a la enseñanza, reciben cerca de $75 \%$ de sus recursos de la subvención otorgada por el Consejo de Financiamiento y cerca de $25 \%$ por concepto de aranceles estudiantiles. En lo referente a investigación, sólo cerca de un tercio de sus ingresos proviene del Consejo de Financiamiento. Aproximadamente, otro tercio procede de los consejos de investigación del gobierno, y un poco más de un tercio, llega en forma de donaciones y contratos de la industria, de organizaciones de beneficencia y de otras instituciones a las que prestan servicios. Las universidades han adoptado un comportamiento muy empresarial. Aparte de los ingresos que perciben por la enseñanza y la investigación, algunas de ellas generan una proporción muy considerable de sus recursos a partir de actividades empresariales, que van desde el arriendo de sus instalaciones para celebrar conferencias, hasta la realización de negocios propios y explotación comercial de sus inventos. Otras aceptan gran cantidad de estudiantes extranjeros, que pagan arancel completo, lo cual les reporta cuantiosas entradas adicionales. En la actualidad hay cerca de 100000 estudiantes extranjeros en el Reino Unido. 
La más empresarial de nuestras universidades obtiene dos tercios de sus ingresos de fuentes distintas de los fondos públicos. Las universidades retienen para sí todo el dinero que puedan percibir por encima de la subvención. No es asunto nuestro, si complementan con otras fuentes el ingreso que reciben del Estado e, incluso, las incentivamos en tal sentido. De hecho, la ley nos prohíbe reducir la subvención atendiendo a los fondos adicionales que puedan generar las propias universidades.

Lo antes dicho certifica que guía nuestra intervención un profundo respeto de la autonomía de las instituciones, principio que influye poderosamente en la manera en que suministramos los fondos. En el mundo hay dos formas básicas de financiar las instituciones de educación superior: en la primera, el órgano de financiación usualmente el Estado, pero en nuestro caso el Consejo de Financiamiento- negocia en detalle con cada universidad lo que ésta se propone hacer y el monto que se le aportará, y, luego, entrega los fondos a cambio de un programa estrictamente definido. Con frecuencia, en caso de que los fondos sean asignados, la asignación se hace conforme a un presupuesto estricto, en el cual los recursos se entregan para usos específicos y deben utilizarse ciñéndose con exactitud a ellos; esto es, tanto para remuneraciones, tanto para bibliotecas y así, sucesivamente. No es posible aplicar esta modalidad en nuestro sistema, pues no resultaría compatible con el alto grado de autonomía a que están habituadas nuestras universidades.

El segundo método general consiste en financiar, ajustándose estrictamente a una fórmula y es el enfoque que hemos adoptado. Calculamos con mucho detalle cómo deben asignarse los fondos, lo que corresponde a enseñanza y a investigación. En lo que respecta a esto último, calculamos cuánto se entrega a los diferentes campos de investigación. Entonces, habiendo hecho detalladamente estos cálculos sobre la base de una fórmula, todo el dinero resultante de estas cuidadosas operaciones lo asignamos en un solo bloque. Sin embargo, no es esto lo esencial del segundo método; lo esencial, y lo que distingue a esta modalidad de la subvención negociada, es que el monto se calcula según una fórmula. Hay mucha discusión en torno al modo en que debe definirse la fórmula, los parámetros que deben formar parte de ella y respecto al valor de estos parámetros. Sin embargo, una vez que eso está zanjado, no hay discusión ulterior. Cada universidad puede calcular por su cuenta cuál es el monto a que tiene derecho, y el Consejo de Financiamiento tiene poca competencia al respecto. El procedimiento impide que seamos persuadidos por argumentos o discusiones, que cedamos a presiones o demos libre curso a nuestros prejuicios al decidir cuánto dinero debe entregarse a cada institución. Todo eso queda zanjado por la computadora.

Desde luego, para que este procedimiento funcione es necesario contar con sistemas sofisticados y bien desarrollados de datos, de recolección y de análisis. No es difícil entender por qué. Estamos asignando miles de millones de libras esterlinas -cerca de 5000 millones ( 7500 millones de dólares) este año- sobre la base única de los datos entregados por las propias universidades acerca del número 
de alumnos que están estudiando tales o cuales materias, y así, sucesivamente. También se requiere un sistema sofisticado y creíble de verificación contable, para garantizar exactitud de los datos utilizados para suministrar los fondos. $Y$ aunque nos consta que las autoridades universitarias son honradas y dignas de fe, sabemos también que pueden cometerse errores, iy cada universidad desea que se le demuestre de manera fehaciente que su vecina no ha cometido un error! En la actualidad, disponemos de todos estos sistemas, pero no fue fácil ni rápido llegar a ello.

El CFESI se encarga de suministrar fondos para la enseñanza y la investigación, y calculamos esos fondos separadamente. En lo que a enseñanza concierne, las universidades tienen dos fuentes de fondos públicos: la subvención que les aportamos, y el arancel pagado por los estudiantes. Cada alumno de tiempo completo cancela un arancel de 1075 libras esterlinas ( 1600 dólares) al año. Esto es una novedad para los estudiantes de tiempo completo (aunque los estudiantes de tiempo parcial siempre han pagado un arancel determinado por las propias universidades, sin ninguna norma nacional.) La cifra de 1075 libras esterlinas se fijó estimando que representaba cerca de la cuarta parte del costo medio de un curso universitario. Es la cifra que las universidades reciben por cada estudiante, pero sólo un tercio de éstos cancelan efectivamente esa cantidad de su propio bolsillo. Y es así porque el arancel se fija a partir de una encuesta sobre los medios económicos del alumnado, de modo tal que el gobierno se encarga de pagar la totalidad del arancel de alrededor de otro tercio de los estudiantes, y de una parte variable del arancel, según la situación económica de los padres, del tercio restante.

Nuestra subvención se entrega conforme al número y la especialidad de los estudiantes inscritos en cada universidad, es decir, tanto, para los estudiantes de ciencias humanas, un poco más para los de ciencias exactas y aún más para los de medicina. A esos aportes básicos se agrega una prima porcentual para los estudiantes de tiempo parcial, para los estudiantes adultos y para los que siguen carreras particularmente largas (entre ellos los estudiantes de postgrado.) También, hacemos aportes adicionales para los estudiantes discapacitados y para aquellos provenientes de familias de escasos recursos. Como el resto de los fondos, los aportes adicionales están incluidos en la fórmula, y su finalidad, por una parte, es hacerse cargo del costo adicional que implica atender a ciertas categorías de estudiantes; y por otra, actuar como canales para encauzar una política determinada: queremos incentivar a las universidades para que inscriban estudiantes de escasos recursos. Básicamente, es muy simple el método que se aplica para financiar la enseñanza.

Calidad, fundamental para el financiamiento

Con todo, es preciso recordar que en el financiamiento de la enseñanza no se considera la calidad de la oferta. En algún momento estudiamos la posibilidad de entregar fondos adicionales a los departamentos calificados como excelentes en el respectivo proceso de evaluación de calidad, pero decidimos no hacerlo, principalmente 
porque desde el punto de vista del estudiante parecía no existir justificación para otorgar menos financiamiento a quienes asistían a cursos de menor calidad. Por el contrario, puede sostenerse que habría que entregar más bien mayores y no menores fondos a la oferta de inferior calidad.

Lo inverso ocurre respecto al financiamiento de la investigación. En efecto, en este plano somos extremadamente selectivos: adjudicamos $75 \%$ de nuestros fondos a sólo $25 \%$ de las universidades, y muchas de las restantes, apenas si reciben fondos por este concepto.

Cada cinco años, se realiza un Ejercicio de Evaluación de la Investigación (EEI), para lo cual formamos grupos especiales de expertos en cada campo para evaluar la calidad de la investigación realizada en la universidad. Estos grupos califican a los diversos departamentos con una escala de siete notas, que van de $5^{*}$ para el departamento cuyo trabajo sobresale en el ámbito internacional, a 1 para aquellos en que muy pocas investigaciones tienen algún mérito ( notas intermedias son $5,4,3 a, 3 b$ y 2.) Estas calificaciones se aplican directamente para nuestro financiamiento: multiplicamos la nota ( 0 , más precisamente, un derivado de la nota: 4.05 para $5 *, 1$ para $3 a$ y 0 para 2 y 1) por el número de investigadores dedicados a cada campo específico en la universidad y, según la calificación resultante, les entregamos una parte de los fondos disponibles para investigación en ese ámbito. Como se advierte, la calidad desempeña un papel decisivo en la asignación de estos recursos. Con igual número de investigadores, un departamento $5^{*}$ recibirá un financiamiento más de cuatro veces superior al de un departamento 3a, y los departamentos calificados con 1 ó 2, no recibirán financiamiento alguno. Y aunque de ello resulta una distribución muy desigual de fondos entre las universidades, creemos que así se garantiza que el lugar de avanzada que ocupa Inglaterra en investigación siga siendo de categoría mundial.

Este artículo sólo ofrece un esbozo muy general de los métodos que aplicamos para financiar las universidades; quienes se interesen en conocer más sobre ellos pueden visitar nuestro sitio web y estudiar, en 'Publications', el documento 'Funding Higher Education in England 01/14', www.hefce.ac.uk, que los describe con mayor detalle. 